\title{
UPDATE: LIVING RETICULATED FILAMENTS FROM HERBSTLABYRINTH-ADVENTHÖHLE CAVE SYSTEM, GERMANY
}

\author{
Leslie A. Melim¹, Diana E. Northup², Michael N. Spilde ${ }^{3}$, and Penelope J. Boston ${ }^{4}$
}

\begin{abstract}
Previous reports of reticulated filaments, an unknown microbe, document that they are ubiquitous in subsurface environments, including limestone caves, lava tubes, and even granite tunnels. Although initial reports of fossil reticulated filaments described preserved organic matter, additional instances involve replacement by calcite, Mn-oxides, silica, or copper silicates. We report on living reticulated filaments found in the limestone Herbstlabyrinth-Adventhöhle Cave System, Hesse, Germany. Samples from soft pool-fingers, pool-bottom clays, and clay-coated rocks along the flow path of incoming water all contain living reticulated filaments associated with abundant biofilm. Most of the reticulated filaments are approximately $0.5 \mu \mathrm{m}$ in diameter, reach lengths between 150 and $200 \mu \mathrm{m}$, and have irregular chambers with spines, a newly identified morphological variant. EDX of these filaments confirms an organic composition not replaced by minerals. They are the dominant visible microbial form in these biofilms, providing hope that they can be isolated and identified.
\end{abstract}

\section{INTRODUCTION}

Reticulated filaments with enigmatic microbial filamentous morphologies were first reported by Melim et al. (2008) from five limestone caves and one lava cave. They described carbon-rich filaments with a diameter of about $0.5 \mu \mathrm{m}$ and lengths up to $75 \mu \mathrm{m}$ that have a cross-hatch or reticulated morphology. Additional examples have since been reported from a variety of subsurface environments. Jones $(2009,2010,2011)$ reported on calcitized examples from cave pearls, terrestrial oncoids, and stalactites from the Cayman Islands. Northup et al. (2011) identified reticulated filaments from a copper-silicate stalactite in a Hawaiian lava cave. Miller et al. (2012) found Mnmineralized reticulated filaments in a granite water tunnel near Oporto, Portugal. Miller et al. (2014) added to the list of lava-cave occurrences with an example from Easter Island, where the filaments are associated with siliceous deposits. This growing list of occurrences for reticulated filaments suggests they are a ubiquitous inhabitant of cave ecosystems, but we still do not know their affiliation.

One difficulty in identifying reticulated filaments is their typically sparse abundance. Although present in a large variety of settings, they are usually a small part of a larger community. Northup et al. (2011) and Miller et al. (2012) both did 16S rDNA clone libraries on samples containing reticulated filaments, but it is impossible to tell which results match up with the filaments. Miller et al. (2012) also cultured samples, but did not successfully culture reticulated filaments. We report here preliminary data from a limestone cave in Germany, where reticulated filaments dominate active pendant biofilm pool fingers and other pool environments. This occurrence confirms the microbial origin and documents samples not mineralized. In addition, the great abundance of reticulated filaments in these samples provides hope they can finally be isolated and identified.

\section{FIELD LOCATION}

The Herbstlabyrinth-Adventhöhle Cave System, Hesse, Germany, formed in the Upper Devonian Iberger Limestone, a reefal deposit built on an isolated seamount (Meyer and Plan, 2010). The limestone is overlain by a clay layer, likely a Mesozoic paleosol, then by Tertiary Westerwald volcanics (Richter et al. 2010, Mischel and Riechelmann, 2013). The volcanics are porous, and the clay layer acts as an aquitard that funnels water into the cave system (Al-Malabeh and Kempe, 2005). Cave pools in the system are either clay-free and coated in calcite spar or clay-rich and covered in clay instead (Fig. 1A). The clayrich pools also contain pendant pool fingers composed of filamentous biofilm (Fig. 1B).

\section{Methods}

Two areas were sampled in 2011, the Rätselhalle in Herbstlabyrinth and an unnamed area in Adventhöhle; the Rätselhalle was resampled in 2014. All samples were collected using sterile techniques into sterile $50 \mathrm{ml}$ vials. After overnight express shipping to the University of New Mexico, glutaraldehyde was added to kill and fix the samples. Several methods have been used in an attempt to separate out

\footnotetext{
${ }^{1}$ Dept. of Geology, Western Illinois University, Macomb, IL 61455, USA

${ }^{2}$ Biology Dept., University of New Mexico, Albuquerque, NM 87131, USA

${ }^{3}$ Institute of Meteoritics, University of New Mexico, Albuquerque, NM 87131, USA

${ }^{4}$ Dept. of Earth and Environmental Science, New Mexico Institute of Mining and Technology, Socorro, NM 87801, USA
} 


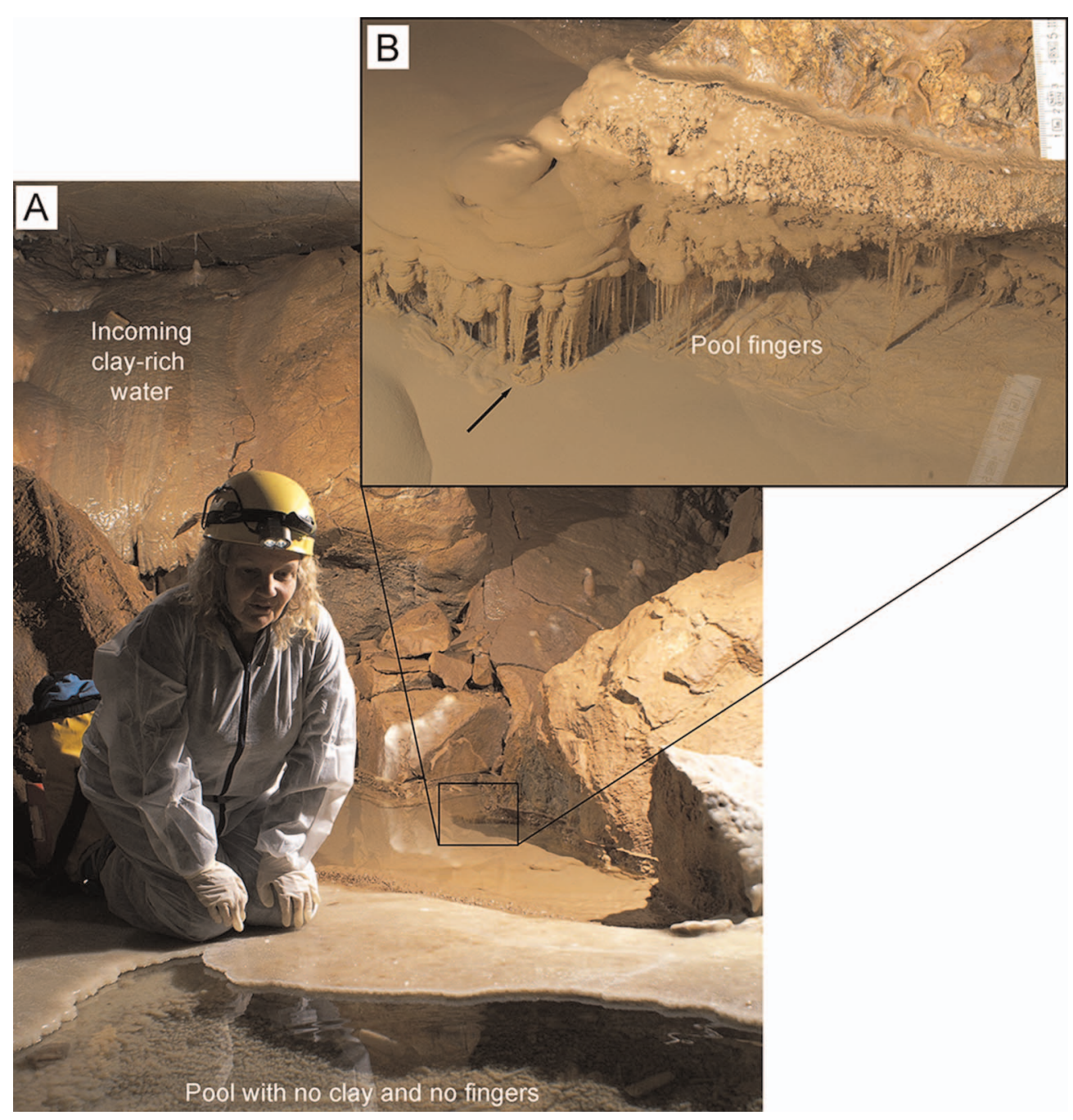

Figure 1. Cave pools in Rätselhalle, Herbstlabyrinth Cave. Diana Northup for scale. 1A: Overview of pools. Pool to the rear has living pool fingers and is fed from above with clay-rich water. Pool to the front has a different, clay-free source and lacks pool fingers. 1B: Closer view of pool fingers with clay. Note coil of pendant clay-covered biofilm on pool bottom (arrow).

filaments from sediment. In 2011, a graded ethanol and water rinse followed by a hexamethyldisilazane rinse was used to clean and dehydrate filaments prior to electron microscopy. However, significant amounts of clay were still retained on the filaments, obscuring their examination. The 2014 samples were treated either with $10 \%$ Na-pyophosphate and $\mathrm{Na}_{2} \mathrm{CO}_{3}$ to disperse clays or with a simple deionized-water rinse. The best results, with the least residual clay, were obtained from the deionized-water rinse after a small amount of clay-rich sample was placed in $40 \mathrm{ml}$ of deionized water, shaken by hand to suspend, then centrifuged for 3 minutes at $300 \mathrm{rpm}$ to settle the $>5-\mu \mathrm{m}$ fraction. The clay-rich liquid was decanted, and the process was repeated until the water was clear and a biofilm sludge remained in the vial. This sludge was smearmounted on an aluminum sample stub and allowed to dry overnight before coating with approximately $200 \AA$ of goldpalladium alloy prior to examination in a JEOL $5800 \mathrm{LV}$ scanning electron microscope at the University of New Mexico. The SEM is equipped with an Oxford Isis 300 energy-dispersive X-ray analyzer.

Figure 2. SEM images of reticulated filaments from Rätselhalle, Herbstlabyrinth Cave. 2A: Smear mount of biofilm, filaments, and clay treated with glutaraldehyde and rinsed with hexamethyldisilazane (from 2011 sample). Most filaments are coated in obscuring clay, but some are reticulated. Box is area in 2B. 2B: Detail from 2A of two reticulated filaments, one with regular chambers aligned in rows, one with irregular chambers partly obscured by clays. 2C: Smear mount of biofilm, 

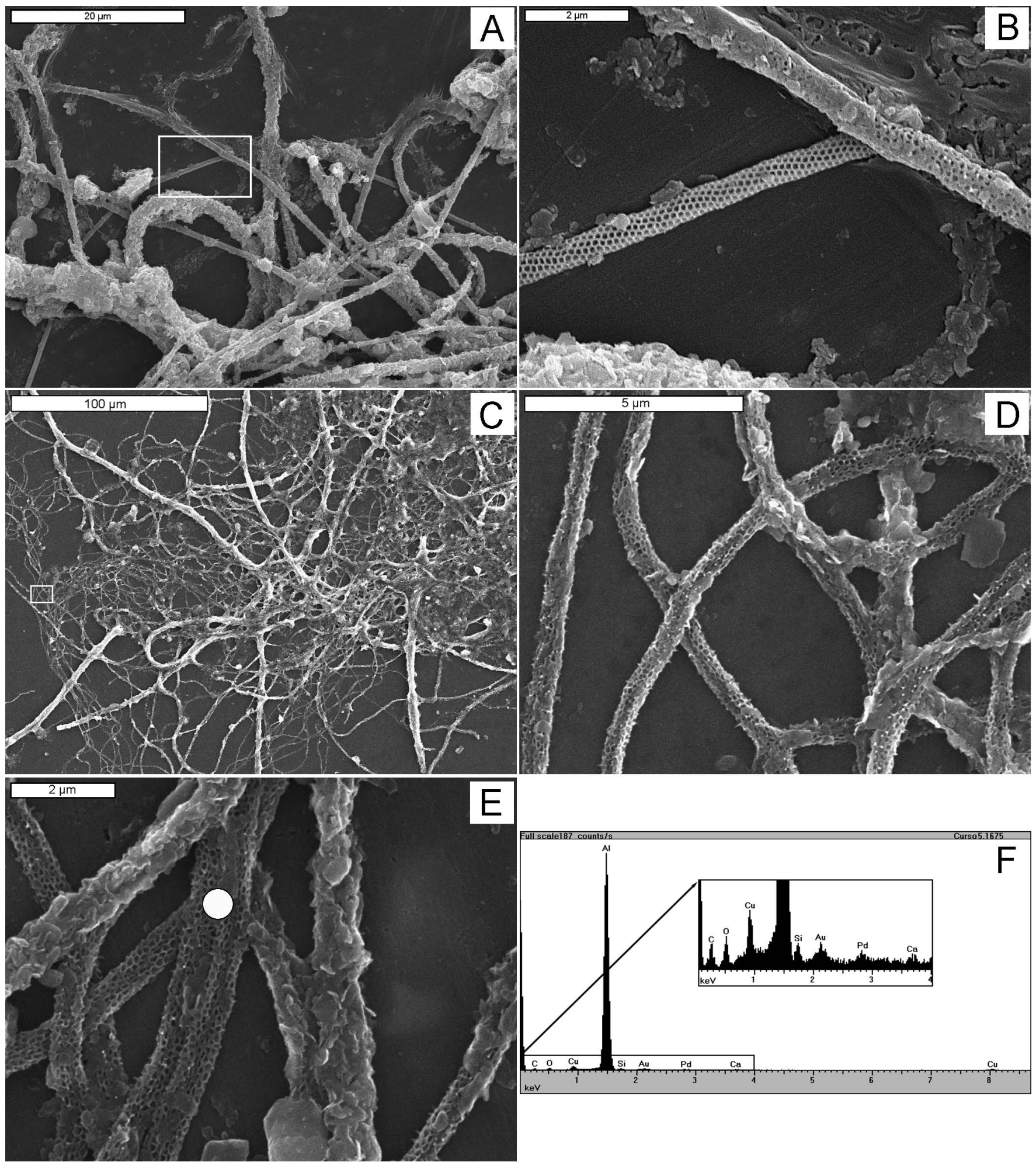

filaments, and clay treated with glutaraldehyde and rinsed in distilled water (from 2014 sample). The nature of the larger filaments, always coated with clay, is unknown. Smaller filaments are all reticulated. Box is area in 2D. 2D: Detail from 2C of reticulated filaments with irregular chambers and small spines. Clays coat some areas. 2E: Close view of reticulated filaments and unknown filaments coated with clays (2014 sample). White dot is location of EDX analysis in 2F. 2F: Energy-dispersive Xray spectrum of reticulated filaments with minor clays, inset is same analysis with expanded scale. Sample mount is aluminum with minor copper, and samples are coated with gold-palladium. The rest of the spectrum includes oxygen, carbon, silicon and trace calcium. 


\section{Reticulated Filaments}

Reticulated filaments were found with biofilm in soft pool-fingers, pool-bottom clays, and clay-coated rocks along the incoming flow path (Fig. 2). Only one sample contains calcite crystals. Samples treated with hexamethyldisilazane are heavily coated in clays, obscuring most of the filaments (Fig. 2A). However, a few filaments are still clearly reticulated (Fig. 2B). The water-rinsed sample has much less residual clay, and two filament sizes are distinguishable, roughly $2-\mu \mathrm{m}$ diameter filaments completely coated in clays and roughly $0.5-\mu \mathrm{m}$ reticulated filaments (Fig. 2C, 2D, 2E). The most common reticulated filament, a new morphology not previously reported, has irregular chambers and small spines (Fig. 2D, 2E) and reaches lengths between 150 and 200 $\mu \mathrm{m}$. Unlike previous examples, reticulated filaments here are a dominant component in the filamentous biofilm (Fig. 2C).

To get an adequate X-ray energy spectrum, several intertwined filaments were analyzed (Fig. 2E, 2F). Minor clay was also present. Removing the influence of the substrate $(\mathrm{Al}, \mathrm{Cu})$, conductive coating $(\mathrm{Au}, \mathrm{Pd})$, and the clays $(\mathrm{Si}, \mathrm{O})$ leaves $\mathrm{C}, \mathrm{O}$, and lesser $\mathrm{Ca}$ as the apparent composition of the filaments (Fig. 2F). Typically calcite in a spectrum shows $\mathrm{Ca}$ much higher than $\mathrm{C}$, but in this case, the filaments have higher $\mathrm{C}$ than $\mathrm{Ca}$. This indicates that the filaments are composed of carbon (likely organic matter) and not replaced by calcite. Noting that these pool fingers were active in the cave prior to sampling and treatment, we conclude that the filaments must be microbial filaments, confirming the interpretation of Melim et al. (2008), Jones (2009, 2010, 2011), Northup et al. (2011), and Miller et al. $(2012,2014)$ that reticulated filaments are an unknown microbe. Ongoing research by our team is working to identify this microbe.

\section{Conclusions}

Reticulated filaments are ubiquitous in cave environments, including limestone caves, lava caves, and even granite tunnels. In the limestone cave Herbstlabyrinth-Adventhöhle Cave System, Germany, living reticulated filaments are present in soft pool-fingers, pool-bottom clays, and claycoated rocks along the incoming flow path. Most of the reticulated filaments are $0.5 \mu \mathrm{m}$ by 150 to $200 \mu \mathrm{m}$ and have irregular chambers with spines. Energy-dispersive X-ray analysis confirms carbon rather than mineral composition. This report of living reticulated filaments still composed of organic matter confirms their microbial nature. Their abundance in this cave provides hope that they can finally be isolated and identified, the subject of ongoing research.

\section{Acknowledgements}

We thank Lukas Plan, Ingo Dorsten, and Stefan Meyer for introducing us to the Herbstlabyrinth-Adventhöhle Cave System and arranging a research permit (Nachforschungsgenehmigung) with the Landesamat für Denkmalpflege Hessen, Germany. Ingo Dorsten, Stefan Meyer, and Simon Mischal are also thanked for their kind hospitality and excellent support during and after our visit. Simon Mischal and Ingo Dorsten collected the additional samples in 2014. The field photographs are by Ingo Dorsten and Stefan Meyer.

\section{REFERENCES}

Al-Malabeh, A., and Kempe, S., 2005, Origin of iron ore nuggets ("Bornerze") through weathering of basalt as documented by pebbles from the Herbstlabyrinth, Breitscheid-Germany: Acta Carsologica, v. 34, no. 2, p. 459-470.

Jones, B., 2009, Cave Pearls-The integrated product of abiogenic and biogenic processes: Journal of Sedimentary Research, v. 79, p. 689 710. doi: $10.2110 /$ jsr.2009.071

Jones, B., 2010, Speleothems in a wave-cut notch, Cayman Brac, British West Indies: The integrated product of subaerial precipitation, dissolution, and microbes: Sedimentary Geology, v. 232, p. 15-34. doi: 10.1016/j.sedgeo.2010.09.003.

Jones, B., 2011, Biogenicity of terrestrial oncoids formed in soil pockets, Cayman Brac, British West Indies: Sedimentary Geology, v. 236, no. 1-2, p. 95-108. doi: 10.1016/j.sedgeo.2010.12.009.

Melim, L.A., Northup, D.E., Spilde, M.N., Jones, B., Boston, P.J., and Bixby, R.J., 2008, Reticulated filaments in cave pool speleothems: Microbe or mineral?: Journal of Cave and Karst Studies, v. 70, p. 135-141.

Meyer, S., and Plan, L., 2010, Pool-fingers - eine kaum bekannte Sinterform biogen Ursprungs: Mitteilungen des Verbandes der deutschen Höhlen- und Karstforsche, v. 56, p. 104-108.

Mischel, S., and Reichelmann, D.F.C., 2013. Fieldtrip to Herbstlabyrinth, in Proceedings Summer School on Speleothem Science, Heidelberg, Germany, Heidelberg University, 10 p. http://www.speleothem2013. uni-hd.de/abstracts_experts/FieldTrip_S4_final.pdf [accessed March 2015]

Miller, A.Z., Hernández-Mariné, M., Jurado, V., Dionísio, A., Barquinha, P., Fortunato, E., Afonso, M.J., Chaminé, H.I., and Saiz-Jimenez, C., 2012, Enigmatic reticulated filaments in subsurface granite: Environmental Microbiology Reports, v. 4, no. 6, p. 596-603. doi: 10.1111/ j.1758-2229.2012.00375.x.

Miller, A.Z., Pereira, M.F.C., Calaforra, J.M., Forti, P., Dionísio, A., and Saiz-Jimenez, C., 2014, Siliceous speleothems and associated microbemineral interactions from Ana Heva Lava Tube in Easter Island (Chile): Geomicrobiology Journal, v. 31, no. 3, p. 236-245. doi: 10.1080/01490451.2013.827762.

Northup, D.E., Melim, L.A., Spilde, M.N., Hathaway, J.J.M., Garcia, M.G., Moya, M., Stone, F.D., Boston, P.J., Dapkevicius, M.L.N.E., and Riquelme, C., 2011, Lava cave microbial communities within mats and secondary mineral deposits: Implications for life detection on other planets: Astrobiology, v. 11, no. 7, p. 601-618. doi: 10.1089/ ast.2010.0562.

Richter, D.K., Meissner, P., Immenhauser, A., Schulte, U., and Dorsten, I., 2010, Cryogenic and non-cryogenic pool calcites indicating permafrost and non-permafrost periods: a case study from the Herbstlabyrinth-Advent Cave system (Germany): The Cryosphere, v. 4, p. 501-509. doi: 10.5194/tcd-4-501-2010. 